\title{
Paving the Way for Academic Medicine
}

The current executive body of Nepal Medical Association (NMA) has realized the need of having an editorial board with experts in the field of scientific writing and critical appraisal. Accordingly, Journal of Nepal Medical Association (JNMA) has formed a new editorial board. It will uplift the quality of journal and its contents in terms of authenticity and reliability. All of the editors have been chosen according to their accomplishment in the scientific community. The voices have already been raised about the need of proper management of journal to provide articles of international standard..$^{1-3}$ Due to the change in NMA executive body every two year, chief editor used to have a lateral entry in the JNMA. But this trend has been abolished with the appointment of current chief editor. With increasing knowledge about the editorial ethics and policy, publishing house and scientific research, the job of an editor has become more specialized than before.

Through years of experience it has been realized that academic medicine will only improve if we start training on scientific writing, peer reviewing, and critical appraisal. Having realized the gravity of the issue JNMA in-house training to the newly appointed editors has been started from this editorial board. Besides this JNMA has started providing editorial training to the medical students and young medical doctors. This training will help them to become a better researchers, author and prospective editor in the future. The training material has been adopted from World Associations of Medical Editors, International Committee of Medical Journal Editors, Councils of Science Editors and Committee on Publication Ethics. ${ }^{4-7}$

Academic medicine is moving ahead, although in a snail pace. However, increasing awareness among health professionals regarding academic medicine, is a welcome sign in the new Nepal, we are talking about. International communication and collaboration is vital for improvement in the organization. Therefore, JNMA has included more international editors in the board. It is believed that this kind of association will be helpful to the journal. JNMA will categorize the entire submitted article according to the level of evidence. This kind of triage will speed up the processing of quality article. Article with higher level of evidence will be scrutinized earlier than others. This will obviously provide opportunity and priority for the high quality research articles in the JNMA. Now onwards, a mandatory biostatistical editor has been appointed. All the research article will be completely reviewed by the biostatistician before it is commissioned to minimize statistical errors. More assistant editors have been appointed to look after different section of the article separately and meticulously, such as checking all the references one by one for its authenticity. The manuscript with more flaws will be rejected immediately. In this way JNMA is trying its level best and is committed to provide high quality article to its readers.

JNMA is abiding by the guidelines developed by International Committee of Medial Journal Editors - Uniform Requirements for Manuscripts Submitted to Biomedical Journals. ${ }^{8}$ From this issue, we are introducing new referencing system called citing medicine - The NLM Style Guide for Authors, Editors and publishers. ${ }^{9}$ It uses full stop after the journal's name, otherwise rest of the things are similar to the Vancouver style with minor variations. Citing medicine is developed by the MedLine/PubMed which we believe, will be uniform system of referencing in the biomedical journal soon. Since our journal is indexed with it, we have adopted this system for editor, author and readers' convenience. We hope that it will help our author to have less tedious job during citing of the manuscript.

In association with NMA, JNMA is coming up with monthly training program on scientific writing, peer review, critical appraisal and editorial training. This activity is intended to help improve academic medicine in Nepal. 


\section{REFERENCES}

1. Research, publication and young doctors. J Nepal Med Assoc 2007 Jan-Mar;46(165):I-II.

2. New Begining. J Nepal Med Assoc 2008;47(172):I-II.

3. Journology - A New Beginning. J Nepal Med Assoc 2009;48(173):I-I.

4. World Association of Medical Editors [Internet]. The World Association of Medical Editors, Secretary, WAME; c2009 [cited 2009 Feb 10]. Available from: http:/ /www. wame.org/.

5. Council of Science Editors [Internet]. Reston, VA: Council of Science Editors; c2009 [cited 2009 Feb 10]. Available from: http://www.councilscienceeditors.org/.

6. Committee on Publication Ethics [Internet]. UK: Committee on Publication Ethics; [cited 2009 Feb 10]. Available from: http://www.publicationethics.org/.

7. International Committee of Medical Journal Editors [Internet]. Philadelphia, USA: International Committee of Medical Journal Editors; c2009 [cited 2009 Apr 2]. Available from: http://www.icmje. org/.

8. Uniform requirements for manuscript submitted to biomedical journals [Internet]. Philadelphia, USA: International Committee of Medical Journal Editors; 1979 [updated 2008 Oct; cited 2009 Apr 2]. Available from: http://www.icmje.org/.

9. Patrias K. Citing medicine: the NLM style guide for authors, editors, and publishers [Internet]. 2nd ed. Wendling, DL, technical editor. Bethesda (MD): National Library of Medicine (US); 2007 [updated 2009 Jan 14; insert Year Month Day]. Available from: http://www.nlm.nih.gov/citingmedicine/. 